\title{
Substantial replacement of lactose with fat in a high-lactose milk replacer diet increases liver fat accumulation but does not affect insulin sensitivity in veal calves
}

\author{
A. J. Pantophlet, ${ }^{* 1}$ W. J. J. Gerrits, † R. J. Vonk, $\ddagger$ and J. J. G. C. van den Borne \\ *Department of Pediatrics, Center for Liver, Digestive and Metabolic Diseases, University Medical Centre Groningen, 9700 RB Groningen, \\ the Netherlands \\ †Animal Nutrition Group, Wageningen University, $6700 \mathrm{AH}$, Wageningen, the Netherlands \\ †Centre for Medical Biomics, University Medical Center Groningen, 9700 RB, Groningen, the Netherlands
}

\begin{abstract}
In veal calves, the major portion of digestible energy intake originates from milk replacer (MR), with lactose and fat contributing approximately 45 and $35 \%$, respectively. In veal calves older than 4 mo, prolonged high intakes of MR may lead to problems with glucose homeostasis and insulin sensitivity, ultimately resulting in sustained insulin resistance, hepatic steatosis, and impaired animal performance. The contribution of each of the dietary energy sources (lactose and fat) to deteriorated glucose homeostasis and insulin resistance is currently unknown. Therefore, an experiment was designed to compare the effects of a high-lactose and a high-fat MR on glucose homeostasis and insulin sensitivity in veal calves. Sixteen male Holstein-Friesian calves (120 $\pm 2.8 \mathrm{~kg}$ of $\mathrm{BW}$ ) were assigned to either a high-lactose (HL) or a high-fat (HF) MR for 13 consecutive weeks. After at least 7 wk of adaptation, whole-body insulin sensitivity and insulin secretion were assessed by euglycemic-hyperinsulinemic and hyperglycemic clamps, respectively. Postprandial blood samples were collected to assess glucose, insulin, and triglyceride responses to feeding, and 24-h urine was collected to quantify urinary glucose excretion. At the end of the trial, liver and muscle biopsies were taken to assess triglyceride contents in these tissues. Long-term exposure of calves to HF or HL MR did not affect whole-body insulin sensitivity (averaging $4.2 \pm 0.5 \times 10^{-2}[(\mathrm{mg} / \mathrm{kg} \cdot \mathrm{min}) /(\mu \mathrm{U} /$ $\mathrm{mL})]$ ) and insulin secretion. Responses to feeding were greater for plasma glucose and tended to be greater for plasma insulin in HL calves than in HF calves. Urinary glucose excretion was substantially higher in HL calves $(75 \pm 13 \mathrm{~g} / \mathrm{d})$ than in HF calves $(21 \pm 6 \mathrm{~g} / \mathrm{d})$. Muscle
\end{abstract}

Received May 28, 2016.

Accepted August 15, 2016.

${ }^{1}$ Corresponding author: a.j.pantophlet@umcg.nl triglyceride content was not affected by treatment and averaged $4.5 \pm 0.6 \mathrm{~g} / \mathrm{kg}$, but liver triglyceride content was higher in HF calves $(16.4 \pm 0.9 \mathrm{~g} / \mathrm{kg})$ than in HL calves $(11.2 \pm 0.7 \mathrm{~g} / \mathrm{kg})$, indicating increased hepatic fat accumulation. We conclude that increasing the contribution of fat to the digestible energy intake from the MR from 20 to $50 \%$, at the expense of lactose does not affect whole-body insulin sensitivity and insulin secretion in calves. However, a high-lactose MR increases postprandial glucose and insulin responses, whereas a high-fat MR increases fat accumulation in liver but not muscle.

Key words: veal calves, lactose, fat, insulin sensitivity

\section{INTRODUCTION}

Veal calves are fed milk replacer (MR) and solid feed (consisting of concentrates and roughages). Despite the tendency in recent years to increase the amount of solid feed, the vast majority $(60-70 \%)$ of the digestible energy intake originates from MR. After feeding, MR bypasses the calf's rumen and directly enters the abomasum because of closure of the esophageal groove. Milk replacer typically contains highly digestible nutrients such as lactose, fat, and proteins, which provide approximately $45 \%, 35 \%$, and $20 \%$ of the digestible energy intake, respectively.

Prolonged intakes of high amounts of MR have been shown to induce problems with glucose homeostasis and insulin sensitivity in heavy ( $>4$ mo of age) veal calves, characterized by high incidences of hyperglycemia and hyperinsulinemia and increased urinary glucose excretion (Hostettler-Allen et al., 1994; Hugi et al., 1997; Pantophlet et al., 2016a). These problems may result in metabolic and pro-inflammatory diseases as seen in humans (Hotamisligil, 2006; Shoelson et al., 2006) and in hepatic steatosis (Gerrits et al., 2008).

Dietary factors contributing to the disturbed glucose homeostasis and insulin sensitivity in heavy calves have been studied (Hugi et al., 1997, 1998; Pantophlet et al., 
2016a), and results indicate that high amounts of lactose may be a factor. Ingesting high amounts of lactose in only 2 daily meals and for a prolonged period (i.e., $\sim 6$ mo of life) deviates from the ontogenetic background of calves. In nature, calves between 4 and 6 mo of age are grazing, and feedstuffs from plant origin are fermented in the rumen, along with short-chain fatty acids being produced as a major energy source. Thus, in nature, a gradual shift occurs from glucose and long-chain fatty acids from milk as main energy sources to short-chain fatty acids originating from rumen fermentation during the first months of the calf's life. In general, problems with glucose metabolism and insulin sensitivity appear to be age dependent in veal calves (Hugi et al., 1997, 1998; Pantophlet et al., 2016b). Heavy veal calves produce very little fatty acids from glucose (Roehrig et al., 1988; van den Borne et al., 2006), and ingestion of large quantities of glucose perturbs their glucose homeostasis for a substantial period after feeding. This circumstance could explain why a high lactose intake negatively affects glucose metabolism and insulin sensitivity in veal calves (Hugi et al., 1997, 1998) and leads to significant amounts of glucose being excreted in urine (Hugi et al., 1997; Pantophlet et al., 2016a).

Alternatively, the high dietary fat content in MR for calves could affect glucose homeostasis and insulin sensitivity. The composition of the digestible energy in veal calves (i.e., high fat and high carbohydrate content) resembles that of the adult Western human diet (Schwarz et al., 2003), and such high dietary fat intake has consistently been associated with the development of insulin resistance (Randle et al., 1963; Storlien et al., 1996; Frayn, 2003; Müller and Kersten, 2003). In rodents, fat-induced problems with insulin sensitivity may operate via several mechanisms, including triglyceride accumulation in skeletal muscle and adipocytes, which impairs GLUT-4 translocation (Storlien et al., 1996), and reduction of the number of insulin receptors in adipocytes (Harris, 1992; Harris and Kor, 1992). However, weaned nonruminant animal species, such as pigs and rodents, do not commonly develop insulin resistance, although they consume higher amounts of glucose (but less fat) than veal calves. We therefore hypothesize that, apart from species differences, interactions between fatty acids and glucose may play a role in perturbing glucose homeostasis and inducing the development of insulin resistance in veal calves.

Standardized studies in which lactose and fat are exchanged (isoenergetically) may reveal the contribution of the dietary energy source to the development of insulin resistance in calves. The objective of the current study was therefore to assess effects of a large isoenergetic exchange of lactose and fat intake on insulin sensitivity in veal calves.

\section{MATERIALS AND METHODS}

\section{Animals and Housing}

Sixteen male Holstein-Friesian calves $(120 \pm 2.8 \mathrm{~kg}$ of BW; $99 \pm 2.0$ d old) were purchased. During the first 6 wk of the 13-wk study, calves were housed in pens of 4 calves each $\left(2 \mathrm{~m}^{2}\right.$ per calf $)$ that were fitted with a wooden slatted floor and galvanized fencings. Calves were then transferred to metabolic cages (dimension: $0.80 \times 1.8 \mathrm{~m})$ for the next $7 \mathrm{wk}$. During this period, several measurements were performed (see Experimental Procedures). Ventilation occurred by ceiling fans, and illumination was by natural light and artificial (fluorescent lamps) light between 0700 and $1900 \mathrm{~h}$. Temperature was controlled at $18^{\circ} \mathrm{C}$ and humidity at $65 \%$.

Experimental procedures complied with the Dutch Law on Experimental Animals and the ETS123 (Council of Europe 1985 and the 86/609/EEC Directive) and were approved by the Animal Care and Use Committee of Wageningen University.

\section{Experimental Design, Diets, and Feeding}

Calves were assigned to either a high-lactose diet $(\mathbf{H L} ; \mathrm{n}=8)$ or a high-fat $\operatorname{diet}(\mathbf{H F} ; \mathrm{n}=8)$, and to 1 of 8 blocks (pairs of calves) with $1 \mathrm{HL}$ calf and $1 \mathrm{HF}$ calf per block. Body weight and age did not differ between treatments at the start of the trial. Because of health problems in $2 \mathrm{HF}$ calves, block 7 consisted of $2 \mathrm{HL}$ calves, and block 8 (with the 2 remaining HF calves) was not included in the insulin sensitivity, insulin secretion, postprandial blood metabolites, and urinary glucose excretion measurements. Between treatments (Table 1), fat and lactose were exchanged isoenergetically based on digestible energy. Energy values of 39.0 $\mathrm{kJ} / \mathrm{g}$ fat and $16.5 \mathrm{~kJ} / \mathrm{g}$ lactose and ileal digestibilities of $95 \%$ for fat and $94 \%$ for lactose were assumed (Hof, 1980). High-lactose diet calves received $25 \%$ more feed than HF calves to obtain isoenergetic and isonitrogenous feeding strategies. Apart from fat and lactose, the daily allowance of protein and micronutrients was similar for the 2 treatments. The feeding level for both MR diets was 2.25 times the digestible energy requirements for maintenance, which was set at $473 \mathrm{~kJ} / \mathrm{kg}^{0.75}$ per day (Van Es et al., 1967). At the start of the study, calves received a commercial MR. Introduction of the experimental MR occurred gradually within the first $3 \mathrm{~d}$ of the study. The feeding schedule was adjusted according to the calf's metabolic weight $\left(\mathrm{kg}^{0.75}\right)$, which was measured weekly. Milk replacer was prepared at a concentration of $167 \mathrm{~g}$ of $\mathrm{MR} / \mathrm{L}$ and provided in a bucket at a temperature of $40-42^{\circ} \mathrm{C}$ at 0800 and 1630 
Table 1. Composition of the high-lactose (HL) and high-fat (HF) milk replacers

\begin{tabular}{lcc}
\hline & \multicolumn{2}{c}{ Diet } \\
\cline { 2 - 3 } Item & $\mathrm{HL}$ & $\mathrm{HF}$ \\
\hline Ingredient $(\mathrm{g} / \mathrm{kg})$ & 396 & 38.0 \\
Whey & 348 & 188 \\
Whey protein concentrate 35\% & - & 150 \\
Whey protein concentrate $75 \%$ & - & 22.2 \\
Delactosed whey & 90.0 & - \\
Lactose & 62.4 & 275 \\
Fat-filled whey palm/coconut ${ }^{2}$ & 70.0 & 238 \\
Fat-filled whey lard ${ }^{2}$ & 20.0 & 62.5 \\
Fat-filled whey coconut & \\
Fat blend & 5.0 & 5.0 \\
Calcium carbonate & 4.0 & 9.2 \\
Monocalcium phosphate & - & 8.1 \\
Magnesium oxide & 0.6 & 1.4 \\
DL-Methionine & 0.5 & 0.6 \\
Premix & 3.2 & 3.4 \\
Nutrients (g/kg) & & \\
CP & 184 & 230 \\
Crude fat & 94 & 300 \\
Crude fiber & 0.01 & 0.01 \\
Crude ash & 65 & 67 \\
Moisture & 21 & 26 \\
Lactose & 591 & 337 \\
Iron (mg/kg) & 72.8 & 56.1 \\
Gross energy (MJ/kg) & 17.9 & 22.6 \\
\hline
\end{tabular}

${ }^{1} \mathrm{HL}$ calves received $25 \%$ more feed than $\mathrm{HF}$ calves to obtain isoenergetic and isonitrogenous feeding strategies.

${ }^{2}$ Total fat composition: lard, $40 \%$; palm oil, $40 \%$; coconut oil, $20 \%$.

h. Milk replacer refusals (maximum of $15 \mathrm{~min}$ after feeding) were weighed and recorded after each feeding. During the first $6 \mathrm{wk}$, calves were tethered with a chain during the MR feeding episodes, allowing individual feeding.

In addition, each calf received $9 \mathrm{~g}$ of $\mathrm{DM}$ solid feed per $\mathrm{kg}^{0.75}$ per day. On a DM basis, the solid feed consisted of $50 \%$ concentrates, $25 \%$ wheat straw, and $25 \%$ maize silage. Solid feed was provided per pen during group housing and per individual calf during individual housing in metabolic cages. Solid feed was provided once daily after feeding MR at $1630 \mathrm{~h}$. Solid feed refusals were weighed and recorded before the morning MR feeding. Throughout the study, calves were allowed ad libitum access to water.

\section{Experimental Procedures}

For all calves (i.e., all 8 blocks), fasting blood samples were taken in wk 1 (before treatment), 6 , and 12 . Liver and muscle tissue samples were taken at slaughter in wk 13. Other measurements were taken during seven 1 -wk measurement periods (wk 7-13) with 1 block (i.e., $1 \mathrm{HF}$ and $1 \mathrm{HL}$ calf for block 1-6 and 2 HL calves for block 7 ) per period ( $\mathrm{n}=14$ calves). These blocks were staggered to allow the laborious measurements and housing in respiration chambers. On d 1 of each measurement period, a euglycemic-hyperinsulinemic clamp was conducted to measure insulin sensitivity. Urine was collected quantitatively from d 2 to 5 for the determination of urinary glucose excretion, postprandial blood samples were taken on d 4 to measure postprandial concentrations of metabolites and hormones, and a hyperglycemic clamp was conducted on day 6 to measure insulin secretion.

\section{Euglycemic-Hyperinsulinemic Clamp}

Whole-body insulin sensitivity was assessed by the euglycemic-hyperinsulinemic clamp technique. Euglycemic-hyperinsulinemic clamps were performed at 202 $\pm 2.9 \mathrm{~kg}$ of BW for HL calves and at $206 \pm 3.6 \mathrm{~kg}$ of $\mathrm{BW}$ for HF calves.

Semipermanent catheters (Careflow, Becton Dickinson, Alphen aan den Rijn, the Netherlands) were inserted in both jugular veins under local anesthesia. The double-lumen catheter in the left jugular vein was used for glucose and insulin infusion and the catheter in the right vein was used for blood sampling during the experimental period. Vicryl suturing (Ethicon, Somerville, NJ) was used to attach the catheter to the skin. The catheter was extended with a 3-layer extension tube to allow infusion and blood sampling.

Calves were fasted for $15 \mathrm{~h}$, and the morning feeding was omitted to achieve a steady glucose turnover rate. Prior starting the 4-h clamp study, 3 blood samples of $5 \mathrm{~mL}$ each were taken at 20 -min intervals. The average glucose concentration from these samples was used to define the basal blood glucose concentration, which was the target glucose concentration during the study. At $1030 \mathrm{~h}$, a priming dose of insulin (Actrapid $100 \mathrm{IE} /$ $\mathrm{mL}$, Novo Nordisk, Denmark) at $2.1 \mathrm{mU} / \mathrm{kg}$ of BW per minute was infused into the left catheter within 5 min to rapidly increase the plasma insulin concentration, immediately followed by a continuous infusion of insulin at a rate of $1 \mathrm{mU} / \mathrm{kg}$ of $\mathrm{BW}$ per minute. This continuous infusion was maintained for a period of 4 $\mathrm{h}$ (plasma insulin levels $\sim 135 \mathrm{mU} / \mathrm{L}$ ). At 5 min after starting the insulin infusion, continuous glucose infusion (20\% glucose solution for intravenous infusion; B. Braun, Melsungen, Germany) was initiated to maintain the basal plasma glucose concentration (i.e., infusion rate depended on the clearance rate). Syringe infusion pumps were used to control infusion rates of glucose and insulin separately, and infusion rates were continuously recorded.

During the clamp study, 0.3-mL blood samples were taken from the right jugular vein catheter at 10-min intervals during the first $2 \mathrm{~h}$ and at 15-min intervals during the second $2 \mathrm{~h}$. Plasma glucose concentration was 
measured in each sample using Precision Xtra Plus test strips in combination with the Precision Exceed Sensor (Abbott, Weesp, the Netherlands). For analyses of insulin and glucose, 5 -mL blood samples were collected at 30-min intervals and transferred into tubes with heparin (insulin) or sodium fluoride (glucose), which were stored on crushed ice. Samples were centrifuged $(1,500 \times g$ for $12 \mathrm{~min})$, and plasma was harvested and stored at $-20^{\circ} \mathrm{C}$ pending further analyses. Catheters were flushed with heparinized saline after each sample to prevent blood coagulation in the catheter.

Depending on the changes in plasma glucose level, the glucose infusion rate during the euglycemic-hyperinsulinemic clamp was adjusted if necessary to maintain a constant, basal plasma glucose level during insulin infusion. Glucose disposal (M-value) was defined as the average glucose infusion rate at steady state divided by BW. Whole-body insulin sensitivity was defined as the M-value divided by the average plasma insulin level at steady state (M/I-value).

\section{Postprandial Blood Glucose, Insulin, and Triglyceride Concentrations}

For assessing metabolic responses to feeding, 8-mL blood samples were taken at $-15,30,60,90,120,150$, $180,240,300,360$, and $420 \mathrm{~min}$ relative to feeding the experimental MR at $0800 \mathrm{~h}$. Blood was transferred into tubes with heparin (insulin, triglycerides) or sodium fluoride (glucose), which were stored on crushed ice. Samples were centrifuged $(1,500 \times g$ for $12 \mathrm{~min})$, and plasma was harvested and stored at $-20^{\circ} \mathrm{C}$ pending analyses. Catheters were flushed with heparinized saline after each sample to prevent blood coagulation in the catheter.

The $\Delta \mathrm{C}_{\max }$ (maximum concentration minus fasting concentration), $\mathrm{T}_{\max }$ (time to maximum concentration), and the incremental area under the curve $\left(\mathbf{i} \mathbf{A} \mathbf{U C}_{0-7 \mathrm{~h}}\right)$ were calculated for all compounds. The iAUC was calculated using the trapezoid method (Le Floch et al., 1990).

\section{Hyperglycemic Clamp}

A 3-h hyperglycemic clamp was conducted to obtain a proxy for insulin secretion under glucose-stimulated conditions. During the first $10 \mathrm{~min}$ of the clamp, plasma glucose was primed by infusing a $20 \%$ glucose solution (B. Braun) intravenously until a glucose level of $10 \mathrm{mmol} / \mathrm{L}$ was reached. Thereafter, blood glucose was measured in 10-min intervals (Precision Extra Plus test strips; Abbott) and the rate of glucose infusion was adapted to maintain the high blood glucose level.
In addition, 8-mL blood samples were taken at 30-min intervals and transferred into tubes with heparin (insulin) or sodium fluoride (glucose), which were stored on crushed ice. Samples were centrifuged $(1,500 \times g$ for 12 min) and plasma was harvested and stored at $-20^{\circ} \mathrm{C}$ pending analyses of glucose and insulin. Catheters were flushed with heparinized saline after each sample to prevent blood coagulation in the catheter.

Insulin secretion was assessed by calculating the total insulin response $\left(\mathrm{iAUC}_{0-3 \mathrm{~h}}\right)$. The iAUC was calculated using the trapezoid method (Le Floch et al., 1990).

\section{Urine Collection}

Harnesses for the fecal collection bags were attached $5 \mathrm{~d}$ before the start of the measurement period to allow separate collection of feces and urine. Urine was quantitatively collected during 4 consecutive days (measurement period d 2-5) in plastic bags that were harnessed to the calves. Urine was collected in a pit containing $750 \mathrm{~mL}$ of $4.5 \mathrm{M}$ sulfuric acid, and samples were taken and stored at $-20^{\circ} \mathrm{C}$ pending glucose analysis.

\section{Fasting Blood Concentrations of Insulin and Metabolites}

After a 15-h fasting period, blood was collected in weeks 1 (before assignment to experimental diet), 6, and 12 from the jugular vein by venipuncture. The 20$\mathrm{mL}$ sample was centrifuged $(1,500 \times g$ for $12 \mathrm{~min})$, and plasma was harvested and stored at $-20^{\circ} \mathrm{C}$ pending analysis of glucose, insulin, HDL- and LDL-cholesterol, triglycerides, malondialdehyde, and nonesterified fatty acids (NEFA).

The quantitative insulin sensitivity check index (QUICKI), which is another index of insulin sensitivity, was calculated from the fasting plasma glucose and insulin concentrations (Chen et al., 2003; Muniyappa et al., 2008). This index was calculated using the following formula:

$$
\text { QUICKI }=\frac{1}{[\log (\text { glucose }, \mathrm{mg} / \mathrm{dL})+\log (\text { insulin, } \mathrm{mU} / \mathrm{L})]}
$$

\section{Liver and Muscle Biopsies}

In wk 13, calves were euthanized by intravenous injection of sodium pentobarbital. The liver and musculus rectus femoris were dissected and sampled. Both tissues were snap-frozen within $15 \mathrm{~min}$ and subsequently stored at $-80^{\circ} \mathrm{C}$ pending analysis of triglyceride concentrations. 


\section{Laboratory Analyses}

Plasma glucose was analyzed on an Architect ci8200 analyzer using the hexokinase method (Abbott Laboratories, Chicago, IL). The within- and between-run coefficient of variation were $\leq 2 \%$. Plasma insulin was analyzed using a Coat-a-Count radioimmunoassay kit (Siemens Healthcare Diagnostics, Erlangen, Germany). The within- and between-run coefficient of variation were $\leq 5 \%$ and $\leq 7 \%$, respectively. Analysis of cholesterol and triglycerides in plasma were performed on a Roche-Hitachi Modular automatic analyzer using enzymatic colorimetric methods (Roche Diagnostics, Almere, the Netherlands). The within- and betweenrun coefficient of variation were $\leq 2 \%$ for both analyses. Plasma malondialdehyde was measured with an isocratic Varian HPLC from Chromosystems (Munich, Germany). A 10-cm C18 cartridge (Varian) was used with a flow rate of $1.0 \mathrm{~mL} / \mathrm{min}$ at ambient temperature $\left(25^{\circ} \mathrm{C}\right)$. Fluorescence detection occurred with excitation at $515 \mathrm{~nm}$ and emission at $553 \mathrm{~nm}$. The within- and between-run coefficient of variation were $\leq 5 \%$ and $\leq 11 \%$, respectively. Plasma NEFA was analyzed with a NEFA-C kit (Wako Chemicals, Neuss, Germany) using a Cobas Mira Plus automatic analyzer (Roche, Basel, Switzerland). The within- and between-run coefficient of variation were $\leq 3 \%$.

Triglyceride concentrations in muscle and liver tissues were analyzed using an enzymatic colorimetric method (GPO-PAP). Slices of 100 to $200 \mathrm{mg}$ of tissues were cut, and $5 \mathrm{~mL}$ of a $25 \% \mathrm{KOH}$ solution was added to saponify triacylglycerols into triglycerides, according to the method of Eggstein and Kreutz (1966). Samples were ground using a homogenizer (Ultra-turrax T8, IKA Labortechnik, Staufen, Germany). After $20 \mathrm{~min}$ in a $70^{\circ} \mathrm{C}$ water bath, triglycerides were converted to

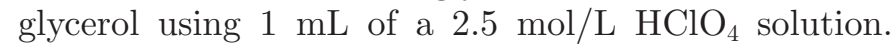
After homogenization, tubes were centrifuged during 5 min at $1,500 \times g$, and the supernatant was harvested and colored using a Liquicolor triglyceride kit (Human Diagnostics Worldwide, Wiesbaden, Germany). The glycerol concentration was spectrophotometrically measured at $546 \mathrm{~nm}$ (Humalyzer 3500, Human). The within- and between-run coefficient of variation were $\leq 6 \%$ and $\leq 8 \%$, respectively.

\section{Statistical Analysis}

SPSS (version 22; IBM Corp., Armonk, NY) statistical software was used for all statistical analyses. Data are presented as means \pm SEM. Whole-body insulin sensitivity, insulin secretion, urinary glucose excretion, and data derived from postprandial blood concentrations (i.e., $\Delta \mathrm{C}_{\max }, \mathrm{T}_{\max }$, and $\mathrm{iAUC}_{0-7 \mathrm{~h}}$ ) were tested for treatment and block effects by ANOVA using the GLM (Univariate) procedure. Treatment and block were used as factors, and calf was the experimental unit.

Liver and muscle triglyceride concentrations were tested for treatment effect by ANOVA using the GLM (Univariate) procedure. Treatment was used as the factor, and calf was the experimental unit. Fasting plasma glucose, insulin, cholesterol, triglycerides, malondialdehyde and NEFA concentrations, and QUICKI (measured longitudinally) were tested for time, treatment, and time $\times$ treatment effects using the mixed effects model procedure. Time, treatment, and their interaction were used as fixed terms, and time as a repeated variable within calf. Only values at weeks 6 and 12 were used as dependent variables. Because calves were on the commercial MR during the initial measurement (values week 1), analysis was performed on delta values (i.e., values at week 6 or 12 minus values at week 1 ). Based on fit statistics (Akaike and Bayesian information criteria), the heterogeneous first-order autoregressive covariance structure was used for all models. When a significant interaction was found, partial tests between per time point were performed. A Bonferroni correction was used to correct for multiple comparisons.

Normality of the model residuals was assessed by visual inspection. Nonnormal distributed data were $(\log )$ transformed to obtain normality. $P$-values $<0.05$ were considered significant, and $P$-values $<0.10$ were considered a trend toward significance.

\section{RESULTS}

Two HF calves had major deteriorations in health (and growth) performance and were excluded from the trial. Therefore, block 7 consisted of 2 HL calves (see Material and Methods). However, none of the outcomes was affected by block; hence, block effects are not reported.

Feed refusal was negligible (i.e., only a few incidences) during the trial in both groups. The average daily gain, measured over the 13-wk trial was 1,366 $\pm 36 \mathrm{~g} / \mathrm{d}$ and did not differ between dietary treatments.

\section{Insulin Sensitivity and Insulin Secretion}

Whole-body insulin sensitivity, measured by the euglycemic-hyperinsulinemic clamp, varied from 1.5 to $8.3[(\mathrm{mg} / \mathrm{kg} \cdot \mathrm{min}) /(\mu \mathrm{U} / \mathrm{mL})]$ between calves and did not differ $(P>0.05)$ between dietary treatments (Figure 1). Pancreatic $\beta$-cell function was assessed by quantification of insulin secretion during the hyperglycemic clamp. Data were available for 12 instead of 14 calves (6 HL and $6 \mathrm{HF}$ ), because some technical difficulties occurred with blood sampling for 2 HL calves 


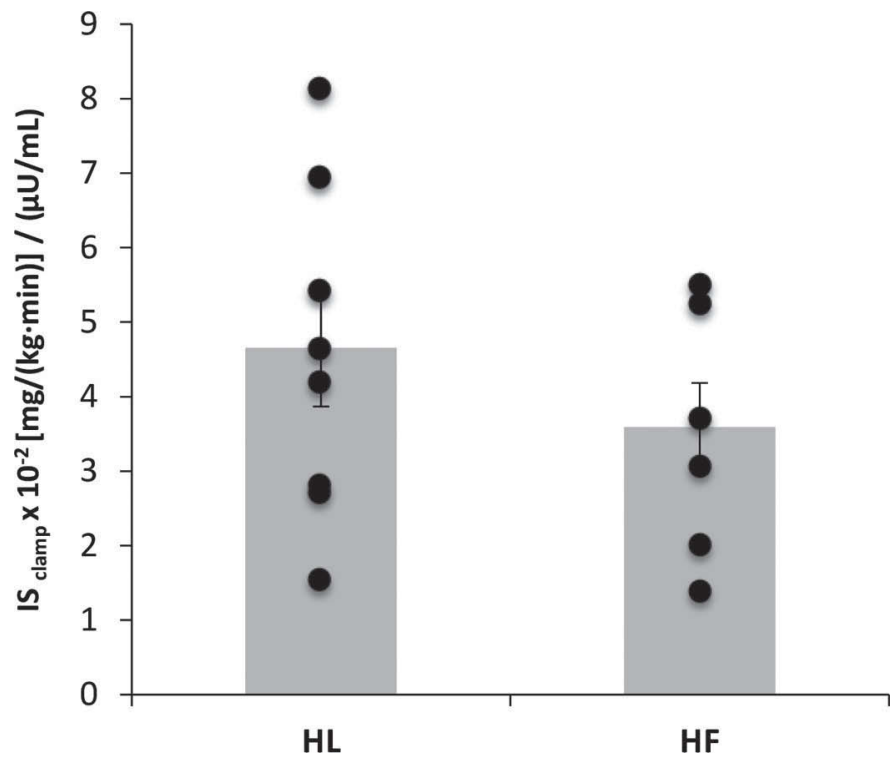

Figure 1. Whole-body insulin sensitivity in veal calves fed a highlactose (HL) milk replacer $(\mathrm{n}=8)$ or a high-fat $(\mathrm{HF})$ milk replacer $(\mathrm{n}$ $=6$ ). Milk replacer compositions are given in Table 1 . $\mathrm{IS}_{\text {clamp }}=$ insulin sensitivity derived from a euglycemic-hyperinsulinemic clamp. Error bars represent SEM, and symbols $(\bullet)$ refer to individual calves. Insulin sensitivity did not differ between dietary treatments.

(not enough blood samples collected). Plasma glucose concentrations reached maximum between 60 and 90 min for both treatment groups, whereas insulin reached maximum concentrations at $120 \mathrm{~min}$ (Figure 2). The total insulin secretion $\left(\mathrm{iAUC}_{0-3 \mathrm{~h}}\right.$ ) did not differ between dietary treatments (Figure 3).

\section{Development of Fasting Blood Metabolites and Hormones}

The change in fasting glucose, insulin, NEFA, and triglycerides over time did not differ between HL and HF calves (Table 2; time $\times$ treatment interaction, $P>$ 0.05). HDL- and LDL-cholesterol concentrations over time differed between treatments (time $\times$ treatment interaction, $P<0.05$ for both). The levels were higher $(P$ $<0.05)$ in HF calves than in HL calves, both in week 6 and 12. Fasting malondialdehyde concentrations tended to differ over time between treatments (time $\times$ treatment interaction, $P<0.10)$. The change in QUICKI, derived from the fasting glucose and insulin concentrations, did not differ $(P>0.05)$ between treatments.

\section{Postprandial Blood Glucose, Insulin, and Triglycerides}

Data were available for 11 instead of 14 calves (6 $\mathrm{HL}$ and $5 \mathrm{HF}$ ), because $1 \mathrm{HF}$ calf did not consume
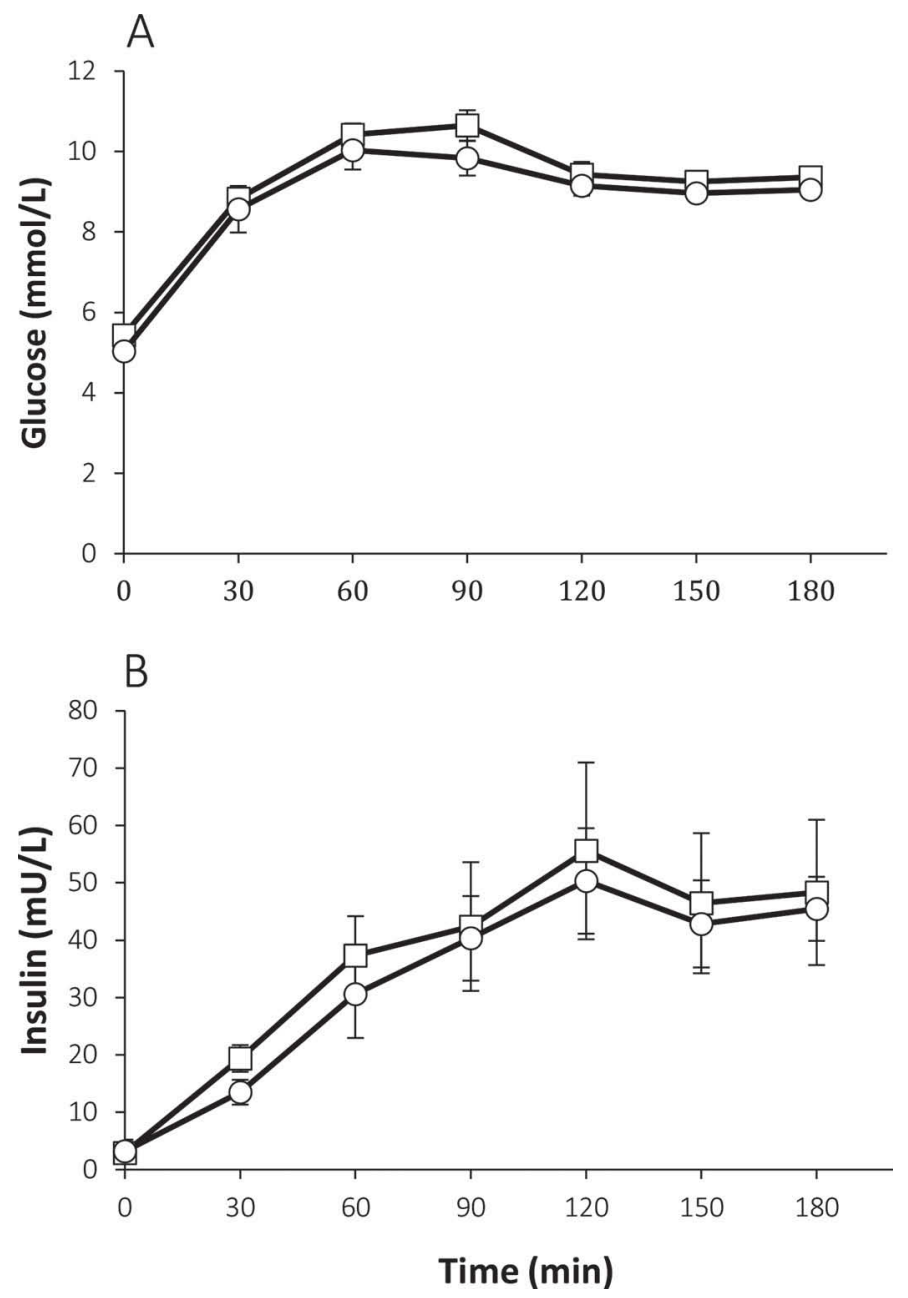

Figure 2. Plasma glucose (A) and insulin (B) concentrations during a 3-h hyperglycemic clamp in veal calves that were adapted to a high-lactose $(\square, \mathrm{n}=6)$ milk replacer or a high-fat $(O, \mathrm{n}=6)$ milk replacer. Error bars represent SEM. Milk replacer compositions are given in Table 1. The total insulin secretion is depicted in Figure 3.

the entire meal on the day of measurement, and some technical difficulties occurred with blood sampling for 2 HL calves (not enough blood samples collected). The postprandial blood glucose, insulin, and triglycerides responses are shown in Figure 4. Fasting blood insulin and triglyceride concentrations did not differ $(P>0.05)$ between treatment groups (Table 3$)$. Fasting glucose concentrations tended to be higher $(P<$ $0.10)$ in HF calves than in HL calves. The $\mathrm{T}_{\max }$ values for glucose, insulin, and triglycerides did not differ $(P$ $>0.05)$ between treatments. For glucose and insulin, $\Delta \mathrm{C}_{\max }$ was higher $(P<0.05)$ in $\mathrm{HL}$ calves, whereas $\Delta \mathrm{C}_{\max }$ for triglycerides was higher in $\mathrm{HF}$ calves. For glucose, $\mathrm{iAUC}_{0-7 \mathrm{~h}}$ for glucose was higher $(P<0.05)$ in $\mathrm{HL}$ calves than in $\mathrm{HF}$ calves. For insulin, the iAUC $\mathrm{A}_{0-7 \mathrm{~h}}$ tended to be higher $(P<0.10)$ in HL calves than in 
Table 2. Fasting plasma metabolite and hormone concentrations (means \pm SEM) in veal calves fed either a high-lactose (HL) milk replacer (n $=8)$ or a high-fat $(\mathrm{HF})$ milk replacer $(\mathrm{n}=6)$ diet (milk replacer compositions are given in Table 1)

\begin{tabular}{|c|c|c|c|c|c|c|c|}
\hline Item & \multicolumn{4}{|c|}{ Treatment (Trt) } & & & \\
\hline \multicolumn{8}{|l|}{ Fasting plasma concentration $^{1}$} \\
\hline Glucose (mmol/L) & $5.1 \pm 0.2$ & $4.9 \pm 0.2$ & $5.8 \pm 0.1$ & $5.6 \pm 0.2$ & 0.102 & 0.132 & 0.847 \\
\hline Insulin (mU/L) & $11.8 \pm 3.4$ & $9.9 \pm 3.5$ & $5.1 \pm 2.4$ & $7.5 \pm 1.8$ & 0.917 & 0.893 & 0.209 \\
\hline Triglycerides $(\mathrm{mmol} / \mathrm{L})$ & $0.09 \pm 0.01$ & $0.08 \pm 0.01$ & $0.11 \pm 0.03$ & $0.10 \pm 0.01$ & 0.321 & 0.263 & 0.784 \\
\hline NEFA $(\mu \mathrm{mol} / \mathrm{L})$ & $281 \pm 35$ & $239 \pm 58$ & $245 \pm 45$ & $295 \pm 147$ & 0.960 & 0.763 & 0.543 \\
\hline Malondialdehyde $(\mu \mathrm{g} / \mathrm{L})$ & $5.5 \pm 0.2$ & $5.7 \pm 0.4$ & $6.3 \pm 0.5$ & $5.1 \pm 0.2$ & 0.092 & 0.278 & 0.072 \\
\hline QUICKI $^{2}$ & $0.357 \pm 0.014$ & $0.346 \pm 0.014$ & $0.341 \pm 0.007$ & $0.349 \pm 0.013$ & 0.636 & 0.835 & 0.298 \\
\hline
\end{tabular}

$\overline{a, b, x, y}$ Different superscripts indicate differences between groups at experimental wk 6 (a, b) or wk $12(\mathrm{x}, \mathrm{y})(P<0.05)$.

${ }^{1} \mathrm{HDL}=$ high-density lipoprotein; LDL = low-density lipoprotein; NEFA = nonesterified fatty acids.

${ }^{2}$ QUICKI $=$ quantitative insulin sensitivity check index (see Material and Methods for details).

HF calves. For triglycerides, iAUC ${ }_{0-7 \mathrm{~h}}$ was higher $(P<$ $0.05)$ in HF calves than in HL calves.

\section{Urinary Glucose Excretion}

Urinary glucose excretion was substantially higher $(P$ $<0.001)$ in HL calves $(75 \pm 13 \mathrm{~g} / \mathrm{d})$ than in HF calves $(21 \pm 6 \mathrm{~g} / \mathrm{d})$.

\section{Liver and Muscle Fat}

Liver triglyceride (fat) content was greater $(P<0.05)$ in HF calves $(16.4 \pm 0.9 \mathrm{~g} / \mathrm{kg})$ than in HL calves $(11.2$ $\pm 0.7 \mathrm{~g} / \mathrm{kg}$ ). Muscle triglyceride (fat) content did not differ $(P>0.05)$ between dietary treatments and was $6.9 \pm 1.5$ and $6.2 \pm 0.4(\mathrm{~g} / \mathrm{kg})$ for HL and HF calves, respectively.

\section{DISCUSSION}

\section{Insulin Sensitivity and Insulin Secretion}

Whole-body insulin sensitivity values were in agreement with results obtained in calves of similar age (Sternbauer et al., 1998a,b; Sternbauer and Luthman, 2002). Cut-off M/I-values for defining insulin resistance in humans during a euglycemic-hyperinsulinemic clamp (cutoff values for calves have not been defined until now) are set at values $<4.4$ to 5.0 (Huan et al., 2010; Lind et al., 1995) Compared with these values, our results, with $50 \%$ of the calves having M/I-values $<4.4$, suggest that our calves were low in insulin sensitivity. This finding corresponds with those from other veal calf studies (Hostettler-Allen et al., 1994; Hugi et al., 1997; Pantophlet et al., 2016a). Increasing the contribution of fat to the digestible energy intake from the MR from 20 to $50 \%$ (at the expense of lactose) did not differentially affect whole-body insulin sensitivity, suggesting that either none or both of these dietary energy sources are equally responsible for the low insulin sensitivity observed in veal calves. These results are in contrast to Palmquist et al. (1992), who studied the effects of high-fat (18\%) and low-fat (10\%) diets on the development of insulin sensitivity in 8- to 16-wk-old veal calves. They found that the high-fat diet did not lead to a decrease in insulin sensitivity, whereas the low-fat diet did lead to a decrease. Their measurements

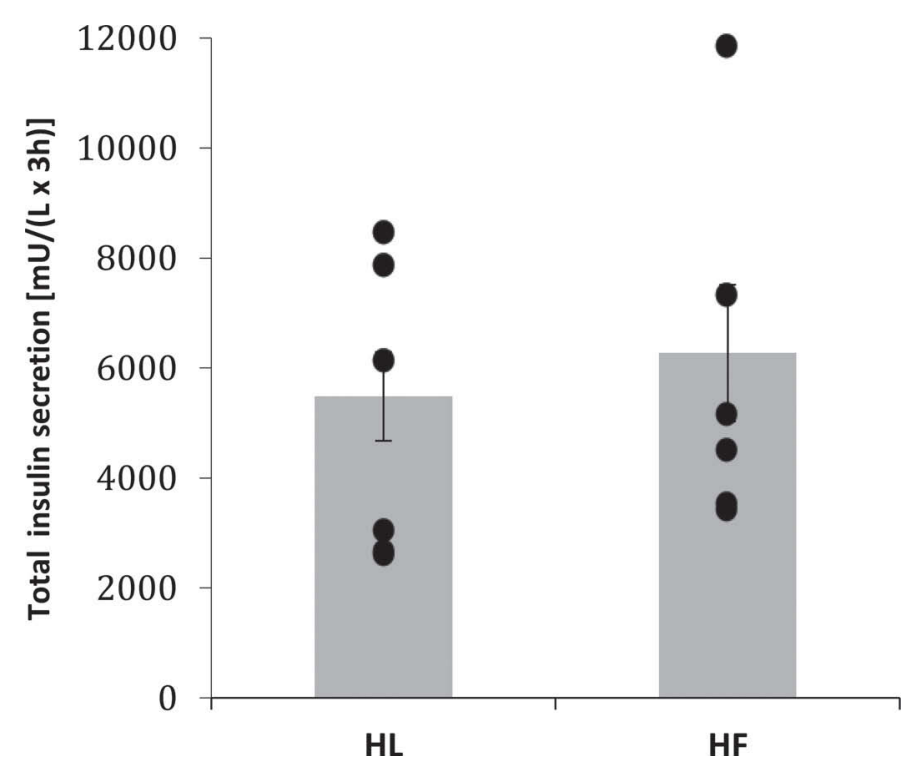

Figure 3. Insulin secretion (assessed during a 3-h hyperglycemic clamp) in veal calves fed a high-lactose (HL; $\mathrm{n}=6$ ) or a high-fat (HF; $\mathrm{n}=6$ ) milk replacer. Milk replacer compositions are given in Table 1. Error bars represent SEM, and symbols (-) refer to individual calves. Total insulin secretion did not differ between treatments. 

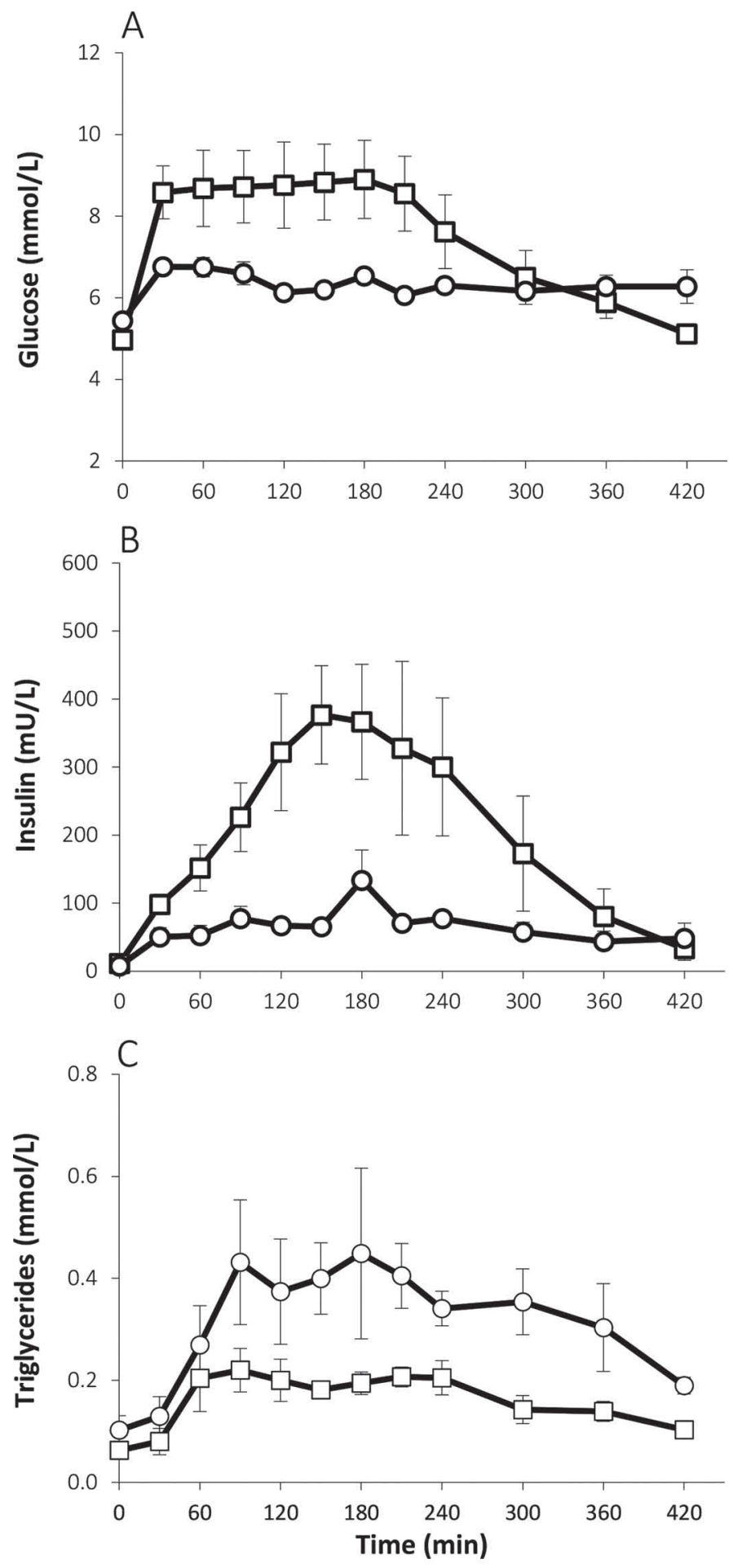

Figure 4. Plasma glucose (A), insulin (B) and triglycerides (C) responses in veal calves fed (at time $=0)$ a high-lactose milk replacer $(\square, \mathrm{n}=6)$ or a high-fat milk replacer $(\bigcirc, \mathrm{n}=5)$. Milk replacer compositions are given in Table 1. Error bars represent SEM. Calculated parameters and statistics are given in Table 3 . of whole-body insulin sensitivity were, however, performed in the fed state ( $4 \mathrm{~h}$ after feeding), when plasma glucose and insulin levels are still elevated, whereas our measurements were performed in the fasting state. Also, the glucose utilization rate, which was used as a measure for insulin sensitivity during an intravenous glucose tolerance test, was not corrected for the total insulin response in their study. When correcting their data for the insulin response (glucose utilization rate/ AUCinsulin), a $<1 \%$ difference in insulin sensitivity remains, suggesting that in their study too, fat intake did not substantially affect insulin sensitivity. The absence of a differential effect of dietary source (fat vs. lactose) on whole-body insulin sensitivity could be explained by the low insulin sensitivity in calves older than 3 mo (Pantophlet et al., 2016b). In a previous study, we found that replacing $33 \%$ of the lactose in MR by glucose, fructose, or glycerol affected postprandial glucose and insulin homeostasis but had no effect on wholebody insulin sensitivity (Pantophlet et al., 2016a). In young calves $(<3 \mathrm{mo})$, insulin sensitivity decreases substantially during the first weeks of life (Stanley et al., 2002; Bach et al., 2013), and the decrease is not affected by extreme contrasts in feeding strategy (e.g., weaning vs. MR feeding; Pantophlet et al., 2016b), indicating that the reduction in insulin sensitivity in calves is dominated by their ontogenetic development. Nonetheless, a higher level of MR feeding may still reduce insulin sensitivity in early life of calves (Yunta et al., 2015). In the current study, insulin secretion (at identical plasma glucose levels) did not differ between treatments groups, indicating that the dietary energy source does not affect the capacity of calves to respond to glucose. This finding corresponds with previous findings in veal calves that were fed a high-lactose vs. a control MR (Hugi et al., 1998). Remarkably, compared with glucose, the response of insulin to a MR meal or glucose infusion is delayed in calves (i.e., $\mathrm{T}_{\max }$ insulin $>\mathrm{T}_{\max }$ glucose), as seen during the hyperglycemic clamp and meal response in our study and other calf studies (Hostettler-Allen et al., 1994; Pantophlet et al., 2016a,b). This delay is, however, not found in humans, rats, and pigs (where $\mathrm{T}_{\max }$ insulin $\leq \mathrm{T}_{\max }$ for glucose; Seki et al., 2005; Eelderink et al., 2012; Souza da Silva et al., 2014). The reason for the delayed insulin response in calves is unclear and warrants further study.

\section{Postprandial Blood Glucose, Insulin, and Triglyceride Homeostasis and Glucosuria}

The maximal postprandial blood glucose concentrations $\left(\Delta \mathrm{C}_{\max }\right)$ and cumulative increase in plasma glucose during the postprandial period $\left(\mathrm{iAUC}_{0-7 \mathrm{~h}}\right.$ ) were higher for HL calves than for HF calves, which was expected 
Table 3. Postprandial responses (means \pm SEM) of glucose, insulin, and triglycerides in veal calves fed either a high-lactose $(\mathrm{HL})$ milk replacer diet $(\mathrm{n}=6)$ or a high-fat $(\mathrm{HF})$ milk replacer diet $(\mathrm{n}=5)^{1}$

\begin{tabular}{|c|c|c|c|}
\hline \multirow[b]{2}{*}{ Item } & \multicolumn{2}{|c|}{ Treatment } & \multirow[b]{2}{*}{$P$-value } \\
\hline & HL & $\mathrm{HF}$ & \\
\hline \multicolumn{4}{|c|}{ Plasma glucose concentration } \\
\hline Fasting values $(\mathrm{mmol} / \mathrm{L})$ & $5.0 \pm 0.2$ & $5.4 \pm 0.2$ & 0.071 \\
\hline$\Delta \mathrm{C}_{\max }(\mathrm{mmol} / \mathrm{L})$ & $4.7 \pm 0.7$ & $1.6 \pm 0.3$ & 0.011 \\
\hline $\mathrm{T}_{\max }(\min )$ & $75 \pm 23$ & $78 \pm 28$ & 0.739 \\
\hline iAUC $_{0-7 \mathrm{~h}}$ & $1,032 \pm 224$ & $369 \pm 71$ & 0.029 \\
\hline \multicolumn{4}{|l|}{ Plasma insulin concentration } \\
\hline Fasting values $(\mathrm{mU} / \mathrm{L})$ & $11.4 \pm 4.0$ & $7.8 \pm 2.7$ & 0.478 \\
\hline$\Delta \mathrm{C}_{\max }(\mathrm{mU} / \mathrm{L})$ & $398 \pm 82$ & $137 \pm 41$ & 0.024 \\
\hline $\mathrm{T}_{\max }(\min )$ & $170 \pm 13$ & $144 \pm 29$ & 0.405 \\
\hline $\mathrm{iAUC}_{0-7 \mathrm{~h}} \times 10^{3}$ & $79 \pm 22$ & $26 \pm 6$ & 0.073 \\
\hline \multicolumn{4}{|c|}{ Plasma triglycerides concentration } \\
\hline Fasting values $(\mathrm{mmol} / \mathrm{L})$ & $0.06 \pm 0.01$ & $0.10 \pm 0.03$ & 0.211 \\
\hline$\Delta \mathrm{C}_{\max }(\mathrm{mmol} / \mathrm{L})$ & $0.20 \pm 0.05$ & $0.49 \pm 0.12$ & 0.036 \\
\hline $\mathrm{T}_{\max }(\min )$ & $150 \pm 29$ & $168 \pm 22$ & 0.646 \\
\hline $\mathrm{iAUC}_{0-7 \mathrm{~h}}$ & $41 \pm 2$ & $83 \pm 13$ & 0.005 \\
\hline
\end{tabular}

because the diet contained significantly larger amounts of lactose. Correspondingly, maximal insulin concentrations were higher for $\mathrm{HL}$ calves and the $\mathrm{iAUC}_{0-7 \mathrm{~h}}$ for plasma insulin tended to be higher. Similarly, the more pronounced postprandial plasma triglyceride response and $\mathrm{iAUC}_{0-7 \mathrm{~h}}$ for triglycerides in $\mathrm{HF}$ calves can be associated with the larger amounts of dietary fat.

Urinary glucose excretion was higher in HL calves than in HF calves, which corresponds to the higher postprandial blood glucose response in HL calves. Glucose excretion is frequently observed in veal calves (Hugi et al., 1997; Vicari et al., 2008; Pantophlet et al., 2016a). A significant correlation $(\mathrm{r}=0.78 ; P<0.01)$ was found between the urinary glucose excretion and $\mathrm{iAUC}_{0-7 \mathrm{~h}}$ for plasma glucose, confirming the association between blood glucose and urinary glucose excretion. Urinary glucose excretion occurs when the renal threshold for glucose reabsorption is exceeded. This threshold varies strongly among individuals, but average values of 8.3 to $11.1 \mathrm{mmol} / \mathrm{L}$ have been reported for calves (Wijayasinghe et al., 1984; Scholz and Hoppe, 1987; Hostettler-Allen et al., 1994). Hence, based on these values, we did not expected urinary glucose excretion in $\mathrm{HF}$ calves. In comparison, calves that were fed a MR in which $33 \%$ of the lactose was replaced by fructose had higher postprandial plasma glucose levels (peak $\sim 8.1$ vs. $6.8 \mathrm{mmol} / \mathrm{L}$ for $\mathrm{HF}$ calves), but only a negligible amount of urinary glucose excretion was found $(\sim 3.6$ vs. $21.0 \mathrm{~g} / \mathrm{d}$ for HF calves; Pantophlet et al., 2016a). The presence of glucose in urine of HF calves cannot be explained with our data, but it might be related to possible (long-term) effects of high dietary fat on renal function.

\section{Fasting Blood Glucose, Insulin, Triglyceride, NEFA, Cholesterol, and Malondialdehyde}

Fasting blood glucose and insulin concentrations did not change over time and did not differ between treatment groups. These results are in agreement with Hostettler-Allen et al. (1994), but in contrast to Palmquist et al. (1992), Hugi et al. (1997), and Pantophlet et al. (2016a), who found an age-related increase in fasting blood insulin concentrations. The QUICKI (an index of insulin sensitivity calculated from fasting blood glucose and insulin concentrations) was not affected by treatment, which is in agreement with the results on whole-body insulin sensitivity obtained from the euglycemic-hyperinsulinemic clamp.

Fasting NEFA concentrations, which are associated with fat catabolism, were not altered during the trial. These finding are in agreement with previous calf studies (Hostettler-Allen et al., 1994; Hugi et al., 1997). Fasting NEFA concentrations also did not differ between dietary treatments (HL vs. HF), indicating that exchanging a part of the dietary lactose with fat does not induce fat catabolism in the fasting state.

Fasting HDL- and LDL-cholesterol concentrations were higher in HF calves than in HL calves during the whole trial period. High amounts of fat intake are known to increase blood cholesterol concentrations (Hostettler-Allen et al., 1994; Siri-Tarino et al., 2010), which might explain the higher cholesterol concentrations in HF calves. In humans, the triglyceride/HDLcholesterol ratio is used to characterize dyslipidemia, which is associated with insulin resistance $(\mathrm{Li}$ et al., 2008; Bitzur et al., 2009). Whether this relationship is 
also true for calves is unknown. Nevertheless, triglyceride/HDL cholesterol ratios were low $(<1)$, suggesting that the current study provided no evidence of dyslipidemia.

Malondialdehyde estimates the level of lipid peroxidation and is a marker of oxidative stress. (Vlková and Celec, 2009). Oxidative stress has been associated with insulin resistance and type 2 diabetes (Tangvarasittichai, 2015). During our study, however, fasting plasma malondialdehyde concentrations were not correlated with QUICKI (i.e., whole-body insulin sensitivity; data not shown), suggesting that oxidative stress does not influence whole-body insulin sensitivity in veal calves.

\section{Liver and Muscle Triglyceride Content}

Liver triglyceride concentrations in our study were lower than in the veal calf study by Gerrits et al. (2008), who reported values between 25.5 and $42.5 \mathrm{~g} /$ $\mathrm{kg}$ (vs. 9.2 and $20.0 \mathrm{~g} / \mathrm{kg}$ in the current trial). Liver triglyceride concentrations were $46 \%$ higher in $\mathrm{HF}$ calves than in HL calves. Excessive fat accumulation in the liver (i.e., hepatic steatosis) is a common metabolic disorder in humans and animals (Bogin et al., 1986), and it has also been linked to insulin resistance and obesity (Gerrits et al., 2008; Fabbrini and Magkos, 2015). Hence, controlling hepatic fat accumulation may improve metabolic health. Triglyceride concentrations in the rectus femoris muscle were similar to previously reported concentrations in the rectus abdominis muscle (5.4 and $7.6 \mathrm{~kg} / \mathrm{g}$ ) and lower than in the semitendinosus muscle (13.5 and $23.9 \mathrm{~kg} / \mathrm{g}$ ) in veal calves (van den Borne et al., 2007). In our trial, muscle triglyceride concentrations did not differ between dietary treatments, which suggests that the dietary source (lactose vs. fat) is unlikely to affect intramuscular fat accumulation in veal calves. Neither the liver nor the muscle triglyceride (i.e., fat) concentrations correlated with QUICKI measured near the end of the trial (i.e., week 12; data not shown), which suggests that the amount of fat in the liver and muscle does not directly influence whole-body insulin sensitivity in veal calves.

\section{CONCLUSIONS}

Increasing the contribution of fat to the digestible energy intake from the MR from 20 to $50 \%$ at the expense of lactose decreased postprandial glucose and insulin homeostasis and reduced urinary glucose losses. Whole-body insulin sensitivity and insulin secretion were not, however, affected by dietary energy source (i.e., high-lactose vs. high-fat MR). The high-fat MR increased liver fat accumulation.

\section{ACKNOWLEDGMENTS}

The authors thank the Dutch Technology Foundation STW, which is part of the Netherlands Organisation for Scientific Research (NWO) and is partly funded by the Ministry of Economic Affairs, and the Product Board Animal Feed (The Hague, the Netherlands) for financially supporting this research. Sven Alferink, Harma Berends, Tamme Zandstra (Animal Nutrition Group, Wageningen University, the Netherlands), Caroline Breit-Corbière (Ecole d'Ingénieurs de Purpan, Toulouse, France), Etienne Labussière (INRA-UMR Pegase, Saint-Gilles, France), and Maria Shipandeni (Department of Animal Science, University of Namibia, Windhoek, Namibia) are gratefully acknowledged for their technical and scientific contributions.

\section{REFERENCES}

Bach, A., L. Domingo, C. Montoro, and M. Terre. 2013. Short communication: Insulin responsiveness is affected by the level of milk replacer offered to young calves. J. Dairy Sci. 96:4634-4637.

Bitzur, R., H. Cohen, Y. Kamari, A. Shaish, and D. Harats. 2009. Triglycerides and HDL cholesterol stars or second leads in diabetes? Diabetes Care 32(Suppl. 2):S373-S377.

Bogin, E., Y. Avidar, and M. Merom. 1986. Biochemical changes in liver and blood during liver fattening in rats. J. Clin. Chem. Clin. Biochem. 24:621-626.

Chen, H., G. Sullivan, L. Q. Yue, A. Katz, and M. J. Quon. 2003. QUICKI is a useful index of insulin sensitivity in subjects with hypertension. Am. J. Physiol. Endocrinol. Metab. 284:E804-E812.

Eelderink, C., M. Schepers, T. Preston, R. J. Vonk, L. Oudhuis, and M. G. Priebe. 2012. Slowly and rapidly digestible starchy foods can elicit a similar glycemic response because of differential tissue glucose uptake in healthy men. Am. J. Clin. Nutr. 96:1017-1024.

Eggstein, M., and F. H. Kreutz. 1966. Eine neue Bestimmung der Neutralfette im Blutserum und Gewebe. Klin. Wochenschr. 44:267273.

Fabbrini, E., and F. Magkos. 2015. Hepatic steatosis as a marker of metabolic dysfunction. Nutrients 7:4995-5019.

Frayn, K. N. 2003. The glucose-fatty acid cycle: A physiological perspective. Biochem. Soc. Trans. 31:1115-1119.

Gerrits, W. J. J., J. J. G. C. van den Borne, and J. W. Blum. 2008. Low-dietary protein intake induces problems with glucose homeostasis and results in hepatic steatosis in heavy milk-fed calves. Domest. Anim. Endocrinol. 35:121-129.

Harris, R. B. S. 1992. Adipocyte insulin responsiveness in female Sprague-Dawley rats fed a low fat diet containing a fat-mimetic carbohydrate. J. Nutr. 122:1802-1810.

Harris, R. B. S., and H. Kor. 1992. Insulin insensitivity is rapidly reversed in rats by reducing dietary fat from 40 to $30 \%$ of energy. J. Nutr. 122:1811-1822.

Hof, G. 1980. An investigation into the extent to which various dietary components, particularly lactose, are related to the incidence of diarrhoea in milk-fed calves. PhD Thesis. Wageningen Agricultural University, Wageningen, the Netherlands.

Hostettler-Allen, R. L., L. Tappy, and J. W. Blum. 1994. Insulin resistance, hyperglycemia, and glucosuria in intensively milk-fed calves. J. Anim. Sci. 72:160-173.

Hotamisligil, G. S. 2006. Inflammation and metabolic disorders. Nature 444:860-867.

Huan, Y., S. DeLoach, C. Daskalakis, S. R. Dunn, K. Sharma, and B. Falkner. 2010. Regulation of transforming growth factor-b1 by insulin in prediabetic African Americans. Kidney Int. 78:318-324. 
Hugi, D., R. M. Bruckmaier, and J. W. Blum. 1997. Insulin resistance, hyperglycemia, glucosuria, and galactosuria in intensively milk-fed calves: Dependency on age and effects of high lactose intake. J. Anim. Sci. 75:469-482.

Hugi, D., L. Tappy, H. Sauerwein, R. M. Bruckmaier, and J. W. Blum. 1998. Insulin-dependent glucose utilization in intensively milk-fed veal calves is modulated by supplemental lactose in an age-dependent manner. J. Nutr. 128:1023-1030.

Le Floch, J. P., P. Escuyer, E. Baudin, D. Baudon, and L. Perlemuter. 1990. Blood glucose area under the curve. Methodological aspects. Diabetes Care 13:172-175.

Li, C., E. S. Ford, Y. X. Meng, A. H. Mokdad, and G. M. Reaven. 2008. Does the association of the triglyceride to high-density lipoprotein cholesterol ratio with fasting serum insulin differ by race/ ethnicity? Cardiovasc. Diabetol. 7:4.

Lind, L., C. Berne, and H. Lithell. 1995. Prevalence of insulin resistance in essential hypertension. J. Hypertens. 13:1457-1462.

Müller, M., and S. Kersten. 2003. Nutrigenomics: Goals and strategies. Nat. Rev. Genet. 4:315-322.

Muniyappa, R., S. Lee, H. Chen, and M. J. Quon. 2008. Current approaches for assessing insulin sensitivity and resistance in vivo: Advantages, limitations, and appropriate usage. Am. J. Physiol. Endocrinol. Metab. 294:E15-E26.

Palmquist, D. L., J. Doppenberg, K. L. Roehrig, and D. J. Kinsey 1992. Glucose and insulin metabolism in ruminating and veal calves fed high and low fat diets. Domest. Anim. Endocrinol. 9:233-241.

Pantophlet, A. J., M. S. Gilbert, J. J. G. C. van den Borne, W. J. J. Gerrits, M. G. Priebe, and R. J. Vonk. 2016b. Insulin sensitivity in calves decreases substantially during the first three months of life and is unaffected by weaning or fructo-oligosaccharide supplementation. J. Dairy Sci. In press.

Pantophlet, A. J., M. S. Gilbert, J. J. G. C. van den Borne, W. J. J. Gerrits, H. Roelofsen, M. G. Priebe, and R. J. Vonk. 2016a. Lactose in milk replacer can partly be replaced by glucose, fructose or glycerol without affecting insulin sensitivity in veal calves. J. Dairy Sci. 99:3072-3080

Randle, P. J., P. B. Garland, C. N. Hales, and E. A. Newsholme. 1963. The glucose fatty-acid cycle. Its role in insulin sensitivity and the metabolic disturbances of diabetes mellitus. Lancet 1:785-789.

Roehrig, K., K. E. Nestor Jr., and D. L. Palmquist. 1988. ATP citrate lyase activity in liver and adipose tissue of veal or ruminating calves (Bos taurus). Comp. Biochem. Physiol. B 90:147-149.

Scholz, H., and S. Hoppe. 1987. Renal glucose loss after intravenous glucose-infusion in calves. Dtsch. Tierarztl. Wochenschr. 94:473476

Schwarz, J. M., P. Linfoot, D. Dare, and K. Aghajanian. 2003. Hepatic de novo lipogenesis in normoinsulinemic and hyperinsulinemic subjects consuming high-fat, low-carbohydrate and low-fat, high-carbohydrate isoenergetic diets. Am. J. Clin. Nutr. 77:43-50.

Seki, T., R. Nagase, M. Torimitsu, M. Yanagi, Y. Ito, M. Kise, A. Mizukuchi, N. Fujimura, K. Hayamizu, and T. Ariga. 2005. Insoluble fiber is a major constituent responsible for lowering the post-prandial blood glucose concentration in the pre-germinated brown rice. Biol. Pharm. Bull. 28:1539-1541.
Shoelson, S. E., S. Lee, and A. B. Goldfire. 2006. Inflammation and insulin resistance. J. Clin. Invest. 116:1793-1801.

Siri-Tarino, P. W., Q. Sun, F. B. Hu, and R. M. Krauss. 2010. Saturated fatty acids and risk of coronary heart disease: Modulation by replacement nutrients. Curr. Atheroscler. Rep. 12:384-390.

Souza da Silva, C., D. Haenen, S. J. Koopmans, G. J. Hooiveld, G. Bosch, J. E. Bolhuis, B. Kemp, M. Müller, and W. J. J. Gerrits. 2014. Effects of resistant starch on behaviour, satiety-related hormones and metabolites in growing pigs. Animal 8:1402-1411.

Stanley, C. C., C. C. Williams, B. F. Jenny, J. M. Fernandez, H. G Bateman, W. A. Nipper, J. C. Lovejoy, D. T. Gantt, and G. E. Goodier. 2002. Effects of feeding milk replacer once versus twice daily on glucose metabolism in Holstein and Jersey calves. J. Dairy Sci. 85:2335-2343.

Sternbauer, K., J. Luthman, A. Hänni, and S. O. Jacobsson. 1998a. Clenbuterol-induced insulin resistance in calves measured by hyperinsulinemic, euglycemic clamp technique. Acta Vet. Scand. $39: 281-289$.

Sternbauer, K., J. Luthman, and S. O. Jacobsson. 1998b. Flumethasone-induced insulin resistance in calves. Zentralbl. Veterinarmed. A $45: 441-443$

Sternbauer, K., and L. Luthman. 2002. Insulin sensitivity of heifers on different diets. Acta Vet. Scand. 43:107-114.

Storlien, L. H., L. A. Baur, A. D. Kriketos, D. A. Pan, G. J. Cooney, A. B. Jenkins, G. D. Calvert, and L. V. Campbell. 1996. Dietary fats and insulin action. Diabetologia 39:621-631.

Tangvarasittichai, S. 2015. Oxidative stress, insulin resistance, dyslipidemia and type 2 diabetes mellitus. World J. Diabetes 6:456-480.

van den Borne, J. J. G. C.. G. E. Lobley, M. W. A. Verstegen, J. M. Muijlaert, S. J. J. Alferink, and W. J. J. Gerrits. 2007. Body fat deposition does not originate from carbohydrates in milk-fed calves. J. Nutr. 137:2234-2241.

van den Borne, J. J. G. C., M. W. A. Verstegen, S. J. J. Alferink, F H. M. van Ass, and W. J. J. Gerrits. 2006. Synchronizing the availability of amino acids and glucose decreases fat retention in heavy preruminant calves. J. Nutr. 136:2181-2187.

Van Es, A. J. H., H. J. Nijkamp, E. J. Van Weerden, and K. K. Van Hellemond. 1967. Energy, carbon and nitrogen balance experiments with veal calves. Pages 197-201 in Energy Metabolism of Farm Animals. K. L. Blaxter, J. Kielanowski, and G. Thorbek, ed Oriel Press, Newcastle-upon-Tyne, UK.

Vicari, T., J. J. G. C. van den Borne, W. J. J. Gerrits, Y. Zbinden, and J. W. Blum. 2008. Separation of protein and lactose intake over meals dissociates postprandial glucose and insulin concentrations and reduces postprandial insulin responses in heavy veal calves. Domest. Anim. Endocrinol. 34:182-195.

Vlková, B., and P. Celec. 2009. Does Enterococcus faecalis contribute to salivary thiobarbituric acid-reacting substances? In Vivo $23: 343-345$.

Wijayasinghe, M. S., N. E. Smith, and R. L. Baldwin. 1984. Growth, health, and blood glucose concentrations of calves fed high-glucose or high-fat milk replacers. J. Dairy Sci. 67:2949-2956.

Yunta, C., M. Terré, and A. Bach. 2015. Short- and medium-term changes in performance and metabolism of dairy calves offered different amounts of milk replacers. Livest. Sci. 181:249-255. 